\title{
Retalho de McGregor para reconstrução de mento
}

\section{McGregor's flap for chin reconstruction}

\author{
Jonatas Catunda de Freitas ${ }^{1,2}$. Camila Sampaio Nogueira². \\ 1 Hospital Universitário Walter Cantídio (HUWC), Fortaleza, Ceará, Brasil. 2 Universidade Federal do Ceará (UFC), Fortaleza, \\ Ceará, Brasil.

\section{RESUMO}

Introdução: O retalho de McGregor, utilizado em reconstruções de cabeça e pescoço, a depender da condição clínica do paciente, pode ser mais vantajoso e benéfico no que tange, principalmente, à redução de morbidades. Objetivo: Relatar caso cirúrgico de reconstrução de mento, utilizando retalho de McGregor, diante da complicação de perda de retalho prévio por técnica usual. Método: Apresentação de caso de paciente diagnosticado com Carcinoma Espinocelular (CEC) em assoalho de boca, beneficiado com retalho de McGregor. Resultados: O paciente apresentou boa evolução funcional e estética após as abordagens cirúrgicas, seguindo sem recidiva. Comentários finais: A técnica utilizada trouxe reabilitação funcional satisfatória ao paciente, visto que foi uma abordagem que favoreceu o procedimento cirúrgico, a recuperação, a estética, e reduziu a possibilidade de complicações cirúrgicas.

Palavras-chave: Retalho Miocutâneo. Carcinoma espinocelular. Neoplasias de cabeça e pescoço. Morbidade.

\section{ABSTRACT}

Introduction: McGregor's flap, used in head and neck reconstructions, depending on the clinical condition of the patient, may be more advantageous and beneficial in reducing morbidities. Objective: To report surgical case of chin reconstruction, using McGregor's flap, facing the complication of previous flap loss by usual technique. Method: Case presentation of patient diagnosed with Squamous Cell Carcinoma (SCC) in the floor of the mouth, benefited by McGregor's flap. Results: The patient presented good functional and aesthetic evolution after the surgicals approaches, without relapse. Final comments: The technique used brought satisfactory functional rehabilitation to the patient, it was an approach that favored the surgical procedure, recovery, aesthetics, and reduced the possibility of surgical complications.

Keywords: Myocutaneous flap. Squamous cell carcinoma. Head and neck neoplasms. Morbidity.

Autor correspondente: Jonatas Catunda de Freitas, Rua Capitão Francisco Pedro, 1290, Rodolfo Teófilo, Fortaleza, Ceará. CEP: $60430-372$. Telefone: +55 85 98834-2772. E-mail: jonatascatunda@hotmail.com

Conflito de interesses: Não há qualquer conflito de interesses por parte de qualquer um dos autores.

Recebido em: 22 Dez 2019; Revisado em: 17 Dez 2020; Aceito em: 03 Mar 2021. 


\section{INTRODUÇÃO}

O retalho de McGregor é uma variante do retalho temporal que se caracteriza pela realização de uma plastia em $\mathrm{Z}$ no final da incisão, cujo objetivo é reduzir a tensão e apropriar a cicatriz em relação às linhas de tensão mínima. ${ }^{1}$ Essa técnica, embora antiga, é vista como uma boa escolha perante a série de meios terapêuticos reconstrutivos.

Diante de pacientes com comorbidade clínicas ou na falta de estrutura técnica, por exemplo, que impeçam ou dificultem o uso de retalhos livres, o retalho de McGregor pediculado é uma excelente alternativa ao cirurgião de cabeça e pescoço. A partir dele, há grande possibilidade de obter bons resultados tanto no quesito estético como funcional.

Relatamos um caso de uso de retalho de McGregor em paciente idoso cujo retalho cirúrgico prévio foi perdido por complicação, que obteve bons resultados funcionais e estéticos diante de sua condição clínica.

\section{RELATO DO CASO}

Paciente masculino, 65 anos, com diagnóstico, no ano de 2013, de Carcinoma Espinocelular (CEC), grau 3, de assoalho de boca anterior, T2N0. Foi submetido, no mesmo ano, à cirurgia de pelveglossomandibulectomia associado à esvaziamento cervical seletivo dos níveis I, II e III bilateral e radioterapia adjuvante. Diante disso, o paciente evoluiu com lesão ulcerada em pele de mento com extensão até mucosa labial, cuja biópsia revelou recidiva do CEC. Foi então submetido, em 2015, à nova ressecção e reconstrução com retalho fasciocutâneo deltopeitoral direito, que apresentou infecção e necrose. No $10^{\circ}$ dia de pós-operatório, o paciente foi submetido à debridamento cirúrgico do Bakamjian, retorno do retalho de Bakamjian ao leito doador e confecção de Retalho McGregor pediculado. Após três semanas, realizou-se o segundo tempo do retalho com secção do pedículo. O paciente, por sua vez, encontra-se bem, até o presente momento, sem evidência de doença, e com resultado funcional e estético bastante aceitável. A área pilosa capilar do retalho reconstruiu a região do mento, permitindo uso de barba para disfarçar o defeito cirúrgico. Submetido e aprovado no Comitê de Ética do referido Hospital de tratamento.

\section{RESULTADO}

O paciente, diante de falha na recuperação da reconstrução de sua lesão com retalho deltopeitoral (Fig. 1.A), teve boa evolução clínica após a abordagem cirúrgica com o Retalho de McGregor (Fig. 1.B) e apresentou uma reabilitação funcional satisfatória. Em segundo tempo, foi feito retorno, após três semanas, do pedículo do retalho (Fig. 1.C), cujo suprimento se dá pela artéria temporal superficial, para o local original após a autonomização da região preceptora.

Em relação à deglutição, o paciente não apresentou engasgos e nenhum episódio de pneumonia aspirativa. Quanto à fala, apresentou-se um pouco prejudicada, mas compreensível. No que tange ao aspecto final, além de favorecer a reconstrução cirúrgica, a utilização do referido retalho em região do mento foi satisfatória quanto a estética, apresentando área capilar na região mentoniana, o que permitiu ao paciente o uso da barba para disfarçar a cicatriz cirúrgica (Fig. 1.D e 1.E).

Figura 1. Intra e pós-operatório de Retalho de McGregor utilizado para reconstrução de mento. A: Infecção e necrose do retalho deltopeitoral direito. B: Retalho frontotemporal pediculado. C: Retorno do pedículo do retalho. D e E: Aspecto final com área capilar do retalho em região do mento.

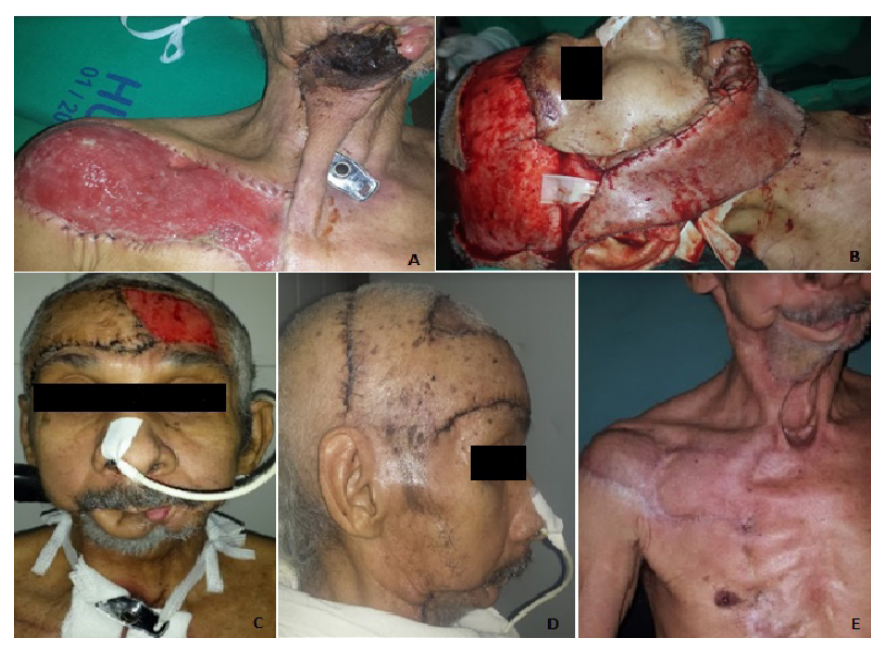

\section{DISCUSSÃO}

Nos últimos anos, técnicas cada vez mais aprimoradas para reconstrução, diante de ressecções amplas de tumores de cabeça e pescoço, vêm sendo utilizadas para um melhor resultado e redução de morbimortalidade e de custos. O uso de retalhos é uma alternativa acessível e com resultado satisfatório. Sabe-se que cada procedimento é único, como afirma Conley, ${ }^{2}$ acompanhado de seus riscos e nunca se obtém perfeição, mas pode beneficiar e favorecer o paciente com o resultado obtido com a reparação.

Diante de lesões extensas, a reconstrução primária fica impossibilitada, seja pela inviabilidade de aproximação direta das bordas livres do defeito, seja pelo comprometimento da mobilidade das estruturas a serem suturadas. A fim de reparar adequadamente o defeito e preservar a função dos órgãos a serem reconstruídos, é necessária a mobilização de tecidos para a devida reconstrução. Nesse contexto, o cirurgião tem à disposição os retalhos livres e algumas opções de retalhos pediculados locais e regionais, como os retalhos de peitoral maior, têmporoparietal e têmporofrontal (ou retalho frontal de McGregor). ${ }^{3}$

McCrory \& Magnuson ${ }^{4}$ descrevem um estudo que compara o uso de retalho livre e retalho pediculado, apontando seus benefícios. Tal pesquisa aponta que taxas hospitalares e permanência em UTI foram significativamente maiores, bem como para a variável tempo operatório, para pacientes submetidos a técnica de retalho livre, o que mostra pontos favoráveis ao uso de retalho pediculado. 
O uso de retalhos exige toda a atenção do cirurgião quanto à irrigação sanguínea, visto que transpor tais estruturas pode pôr em risco sua drenagem arterial e levar à necrose do retalho, podendo ser necessária a realização de outro procedimento cirúrgico para reabordar a implantação de retalhos.

Nesse contexto, Shipkov et $\mathrm{al}^{5}$ afirmam que o retalho têmporofrontal para a reconstrução em um único tempo cirúrgico pode ser o método de escolha para reconstrução em alguns sítios anatômicos, como em órbita. Porém, a reconstrução imediata com esta técnica após ressecção do tumor pode dificultar a detecção de uma recidiva local. ${ }^{6}$

Há particularidades significantes no retalho frontal de McGregor. Ele é um relativamente fino, maleável, bem vascularizado pelos vasos temporais superficiais e se adapta

\section{REFERÊNCIAS}

1. Leite I, Vieira R, Figueiredo A. Reconstrução palpebral em cirurgia dermatológica. Trab Soc Port Dermatol Venereol. 2011;69(2):22735 .

2. Conley J. Use of composite flaps containing bone for major repairs in the head and neck. Plast Reconstr Surg. 1972;49:522.

3. Vanni CM, Pinto FR, Castro R, Kanda JL. Retalho pediculado temporofrontal para reconstrução de defeitos em cabeça e pescoço. Arq Bras Ciên Saúde. 2010;35(2):99-102. facilmente aos contornos anatômicos. Seu pedículo pode ser dissecado com segurança até o nível do conduto auditivo externo, sem risco de lesão do nervo facial, proporcionando, assim, um grande arco de rotação ao retalho, além de ser uma forma de reconstrução segura e de técnica cirúrgica simples. ${ }^{3}$ No entanto, convém destacar que o retalho apresentado é uma opção de exceção e que apresenta sérias limitações, principalmente o dano estético.

Portanto, por trás de limitações e cuidados ao uso do retalho frontotemporal, e diante de outras opções de reconstrução, o retalho de McGregor é uma alternativa viável, segura, acessível e que reduz morbidade, de acordo com as características clínicas do paciente, favorecendo uma reabilitação funcional significativa ao paciente.

4. Mccrory AL, Magnuson JS. Free tissue transfer versus pedicled flap in head and neck reconstruction. Laryngoscope. 2002;112(12):21615.

5. Shipkov HD, Zheliazkov HB, Anastassov YK. One-stage reconstruction of the eye socket with vascularized temporalis muscle flap in orbital exenteration. Folia Med (Plovdiv). 2001;43(3):41-6.

6. Potparic Z, Starovic B. Reconstruction of extensive defects of the cranium using free-tissue transfer. Head Neck. 1993;15(2):97-104.

\section{Como citar:}

Freitas JC, Nogueira CS. Retalho de McGregor para reconstrução de mento. Rev Med UFC. 2021;61(1):1-3. 